\title{
Genetic polymorphism of Hucul horse population based on 17 microsatellite loci*
}

\author{
Agnieszka Fornal ${ }^{\bigotimes}$, Anna Radko and Agata Piestrzyńska-Kajtoch \\ National Research Institute of Animal Production, Department of Cytogenetics and Molecular Genetics of Animals, Balice n. Kraków, Poland
}

\begin{abstract}
Short tandem repeat (STR) loci, i.e. microsatellites are a class of genetic markers commonly used for population studies and parentage control. This study determined the usefulness of microsatellite markers recommended by International Society for Animal Genetics (ISAG) for identification and pedigree analysis in horses based on the example of Polish Hucul horse population (Equus caballus). The set of seventeen microsatellites loci was tested (AHT4, AHT5, ASB2, HMS2, HMS3, HMS6, HMS7, HTG10, HTG4, HTG6, HTG7, VHL20, ASB17, ASB23, CA425, HMS1, LEX3) for 216 individuals. All samples were genotyped and mean number of alleles per locus was estimated (7.00). Means of observed $\left(\mathrm{H}_{0}\right)$ and expected $\left(\mathrm{H}_{\mathrm{e}}\right)$ heterozygosity were calculated 0.7288 and 0.7027 , respectively. The observed heterozygosity was similar to the results of research on Hucul horse population in another area of Carpathians Mountains. The average polymorphism information content (PIC) for analyses of seventeen microsatellite markers indicates the usefulness of this set of markers for Hucul horse parentage testing.
\end{abstract}

Key words: microsatellite markers, STR, parentage testing, horse, Hucul horse, indigenous breeds

Received: 13 October, 2013; revised: 03 December, 2013; accepted: 12 December, 2013; available on-line: 28 December, 2013

\section{INTRODUCTION}

Short tandem repeat (STR) loci, i.e. microsatellites are a class of genetic markers commonly used for population studies and parentage control. Due to their high level of polymorphism and co-dominant inheritance, microsatellites are used in individual identification and parentage testing. DNA markers could be used inter alia, for: examination of genetic structure of populations, estimation of degree of inbreeding or admixture, homozygosity, genetic distance between populations and breeds, planning of crossbreeding programs, preserve programs (maintenance of autochthonous populations and gene-reserve in indigenous breeds), and so on (Józsa et al., 2005).

Generally, in horses (Equus caballus) set of twelve basic microsatellites loci (AHT4, AHT5, ASB2, HMS2, HMS3, HMS6, HMS7, HTG10, HTG4, VHL20, ASB17 and ASB23) and five additional microsatellites loci (HTG6, HTG7, CA425, HMS1 and LEX3) are used (Equine Genetics and Parentage Analysis Workshop, 2012). This horse genotyping kit has been designed to provide high discrimination power (PD), with minimum time need to sample preparation and minimum use of reagents (Dimsoski, 2003) Those markers constitute panel of loci recommended by International Society for Animal Genetics
(ISAG) in horses parentage testing. Microsatellites loci constitute an informative source concerning population history, structure and genetic diversity (Georgescu \& Costache, 2012; Tautz, 1989).

There has been a rapid decline in numbers within many breeds of horses, including Hucul horses in past century. Hucul horse is primitive breed descended from a wild mountain horse, similar to Tarpan (Equus ferus seu gmelini). According to some sources, Hucul horse is probably a descend of Tarpan and has similar morphological characteristics. Unfortunately, comparison of Hucul horse and Tarpan is impossible, because this subspecies extincted in 1879, in Ukraine. However, the opinions about the origin and breed formation are not uniform. Scientists also assume that Hucul horse is a direct descendant of the Tarpan, and accordingly, the very old Mongolian horse, mountain horse, old Polish horse, old Moldavian horse - consequently, in different modifications of mountain Tarpan type. Some blood impacts of Arabian horses, Lipican, Hafling, Norik breed, Ford and other breeds in the breed formation were observed.

Hucul horse is small in type, mountain horse breed and originated from Hucul in east part of Carpathian Mountains area. The name of the breed it is the name after a small human ethnic group (Hutsul), who lived in the forests of the Carpathian Mountains, although the breed of Hucul horse is much older than this ethnic group. In 1603 the first written reference about Hucul horse of Bucovina appeared as a mountain horse from Carpathian Mountains, characterising great adaptation capabilities to difficult natural conditions. Hucul horse was bred in the former countries of the Austro-Hungarian Monarchy and Poland. Nowadays, this horse is considered as the most valuable equine material in Carpathian Mountains area. There are sources assigning phylogenetic closeness to Oriental horse and Polish Konik horse also, because of descending directly form Tarpan horse (Bordzoł \& Jackowski, 2008; Georgescu et al., 2008; Kusza et al., 2013; Trandžík et al., 2006; Žídek et al., 2009).

The breed of Hucul horse has been known not only in Austro-Hungarian Monarchy area. The breeding was also extended to Finland, United Kingdom, Germany, France and even to the Republic of South Africa. At present, the estimated number of Hucul horses is 2000, the traditional breeding centres of the Hucul horses are Poland and Romania. According to references, population of Polish Hucul mares in studbooks were estimated

e-mail: agnieszka.fornal@izoo.krakow.pl

*Presented at the 5th Central European Congress of Life Sciences „EUROBIOTECH 2013”, Kraków, Poland. 
Table 1. Locus descriptions for seventeen equine microsatellites loci (Van de Goor et al., 2009, Dimsoski, 2003)

\begin{tabular}{|c|c|c|c|c|c|}
\hline Locus & $\begin{array}{l}\text { Lokalization on } \\
\text { chromosome }\end{array}$ & Repeat motif & Reference & $\begin{array}{l}\text { Size Range } \\
\text { (bp) }\end{array}$ & Fluorescent dye \\
\hline AHT4 & $24 q 14$ & $(A C)_{n} A T(A C)_{n}$ & Binns et al. (1995) & $144-164$ & 6-FAM \\
\hline AHT5 & 8 & $(G T)_{n}$ & Binns et al. (1995) & $126-144$ & VIC \\
\hline ASB2 & $15 q 21.3-q 23$ & $(G T)_{n}$ & Breen et al. (1997) & $216-250$ & $\mathrm{VIC}$ \\
\hline ASB17 & $2 p 14-p 15$ & $(A C)_{n}$ & Breen et al. (1997) & $87-129$ & PET \\
\hline ASB23 & $3 q 22.1-q 22.3$ & $(\mathrm{TG})_{\mathrm{n}}$ and $(\mathrm{TG})_{n} T(\mathrm{TG})_{4}$ & Irvin et al. (1998) & $175-211$ & VIC \\
\hline CA425* & $28 q 18$ & $(G T)_{n}$ & Eggleston-Stott et al. (1997) & $226-246$ & PET \\
\hline $\mathrm{HMS1}^{*}$ & 15 & $(\mathrm{TG})_{\mathrm{n}}$ & Guerin et al. (1994) & $170-186$ & PET \\
\hline HMS2 & 10 & $(C A)_{n}(T C)_{2}$ & Guerin et al. (1994) & $222-248$ & NED \\
\hline HMS3 & 9 & $\begin{array}{l}(\mathrm{TG})_{2}(\mathrm{CA})_{2} \mathrm{TC}(\mathrm{CA})_{\mathrm{n}} \text { and }(\mathrm{TG})_{2}(\mathrm{CA})_{2} \mathrm{~T}- \\
\mathrm{C}(\mathrm{CA})_{\mathrm{n}} \mathrm{GA}(\mathrm{CA})_{5}\end{array}$ & Guerin et al. (1994) & $148-170$ & NED \\
\hline HMS6 & 4 & $(G T)_{n}$ & Guerin et al. (1994) & $151-169$ & VIC \\
\hline HMS7 & $1 q 25$ & $(A C)_{2}(C A)_{n}$ & Guerin et al. (1994) & $165-185$ & 6-FAM \\
\hline HTG4 & 9 & $(\mathrm{TG})_{\mathrm{n}} \mathrm{AT}(\mathrm{AG})_{5} \mathrm{AAG}(\mathrm{GA})_{5}, \mathrm{ACAG}(\mathrm{AGGG})_{3}$ & Ellegren et al. (1992) & $127-139$ & 6-FAM \\
\hline HTG6* & $15 q 26-q 27$ & $(\mathrm{TG})_{\mathrm{n}}$ & Ellegren et al. (1992) & $84-102$ & VIC \\
\hline $\mathrm{HTG}^{*}$ & 4 & $(G T)_{n}$ & Marklund et al. (1994) & $118-128$ & NED \\
\hline HTG10 & 21 & $(\mathrm{TG})_{\mathrm{n}}$ and $\operatorname{TATC}(\mathrm{TG})_{\mathrm{n}}$ & Marklund et al. (1994) & $95-115$ & NED \\
\hline LEX3* & $\mathrm{Xq}$ & $(\mathrm{TG})_{\mathrm{n}}$ & Coogle et al. (1996) & $142-164$ & PET \\
\hline VHL20 & 30 & $(\mathrm{TG})_{\mathrm{n}}$ & Van Haeringen et al. (1994) & 87-105 & 6-FAM \\
\hline
\end{tabular}

*Additional microsatellites markers in STRs set

for 1120 individuals, as in 2008. In 2009, there were qualified 919 Hucul mares to the conservation of genetic resources (Tomczyk-Wrona, 2009).

Hucul horse has heavy build and features of a wild horse with endurance against low temperature and resistant to diseases. Hucul, as a breed, has been formed by natural selection up to present time (Georgescu et al., 2008; Georgescu et al., 2011). Hucul is strong, skillful horse breed for endurance in mountain terrain. Hucul horse reaches $350-450 \mathrm{~kg}$ of body weight and 125-145 $\mathrm{cm}$ height at the withers.

At the present time, Hucul horse breed is independent and unique one. The first stud farm was established in 1856 at Roaduti, in Romania. In 20th Century the breed's herd was moved from Lucina to Waldof, in Austria. After the end of the World War I only 300 Hucul horses has remained and purity of the breed has been weaken. This is one of the horse breeds classified on the "Red List" of domestic animal breeds as threatened by extinction (Źídek et al., 2009). According to the value of breed, since 1979 the breed has been a part of a protected gene fund of original and primitive breeds of the Food and Agricultural Organization (FAO). In 1994 the Hucul International Federation (HIF) was established, mainly to create breeding goals in Hucul breeder countries. This conservation of breed was gradually extended to particular countries: Poland, Romania, Ukraine, Hungary, Austria, the Czech Republic and Slovak Republic. According to Žídek et al. (2009) Czech Hucul population seems to be isolated from another populations, Slovak and Polish Hucul horses are closely related and slightly admixed.
Hucul horse is one of the oldest and indigenous breeds in Poland (Bordzoł \& Jackowski, 2008; Food and Agriculture Organization DAD-IS database, 2013; Georgescu \& Costache, 2012; Józsa et al., 2005; Kusza et al., 2013). Protection of genetic resources of this breed is important as Hucul horse is endangered protected relic of nature and cultural heritage of the Carpathians needs to be preserved, as well. Most of all, on the grounds of a small size of Hucul horse population (Bordzol \& Jackowski, 2008), and unique character of a breed, Hucul's genetic variation should be monitored to preserve biodiversity within species (Bordzol \& Jackowski, 2008; Georgescu et al., 2008; Georgescu et al., 2011).

According to Kusza et al. (2013), studbook data contains some errors in the registration of the Hucul studbook. Those data might be important to conservation of the breed and correct lines of ancestral might be essential for Hucul breed and breeding. This information might be verified by a molecular data as well as mitochondrial DNA research. It is essential especially because cultural and historical arguments for conservation have not been confirmed in the genetic data yet. The microsatellite markers and mitochondrial sequences variation could reveal information about history of breed and genetic background of the Hucul horse, population structure, genetic characterization and also phylogenetic evolutionary relationship to another primitive equine breeds (Kusza et al., 2013).

Characteristics of genetic variability of local breeds, i.a. Hucul horse, is substantial as a one of the global priorities of scientific research to maintain the genetic resources in opposition to the aims dictated by practices 
in livestock breeding (Georgescu \& Costache, 2012). The research based on molecular markers could be useful in conservation strategy and Hucul horse breeding program (Kusza et al., 2013). The analyses using microsatellites loci were conducted for many different horses breeds during the last few years. The genetic variation was also tested for Hucul horse populations in Romania and individuals from Hungary, Austria and Slovak republic. Until now, analyses of genetic diversity of Hucul horse based on STRs were conducted for 60 individuals from Romania (using 12 STRs) (Georgescu et al., 2008), for 71 individuals form Hungary, Austria and Slovakia (using 17 STRs) (Kusza et al., 2013) and for 81 individuals form Hungary (using 17 STRs) (Józsa et al., 2005). There wre also analyses with Polish individuals (Hucul horses originated from Slovak republic, Poland and Czech Republic) (using 10 STRs).

\section{MATERIAL AND METHODS}

In the present study on Hucul horse populations, 216 blood samples from three distinct Hucul horse populations form Subcarpathian Voivodeship (West Carpathian Mountains) were used. The analyses were carried out on 91 individuals from first population, on 85 individuals from second population and on 40 individuals from the third population. Because of lack of differentiation in genetic structure among those three populations, the analyses were conducted for all studs as a one population. Each sample of DNA was isolated from $300 \mu \mathrm{l}$ of blood using Wizard kit (Promega — Wizard Genomic DNA Purification Kit)) according to the manufacturer's protocol. DNA was amplified in one multiplex reaction using Finnzymes Diagnostics kit (Thermo Scientific). Amplification of STRs was conducted with GeneAmp 9700 System (Applied Biosystems) using the following cycling conditions: $98^{\circ} \mathrm{C}$ for 5 min followed by 30 cycles of $\left(98^{\circ} \mathrm{C}\right.$ for $15 \mathrm{~s}$, annealing temperatures $60^{\circ} \mathrm{C}$ for $75 \mathrm{~s}$, $72^{\circ} \mathrm{C}$ for $30 \mathrm{~s}$ ) and $72^{\circ} \mathrm{C}$ for $5 \mathrm{~min}$ (Instruction Manual. 2011). The set of proofreading activity and fluorescently labelled 17 primers specific for STRs was tested. PCR products were separated in a capillary electrophoresis system on the $3130 \times 1$ Genetic Analyser (Applied Biosystems). The GeneScan-500 LIZ Size Standard was used in each sample run for an application of automated DNA fragments analysis with five fluorescent dyes (Table 1). Analysis of DNA profiles for 17 STR loci was conducted in GeneMapper 4.0 software (Applied Biosystems). DNA control from the kit was used.

Statistical analysis was conducted using GenAlEx6 (Peakall \& Smouse, 2006) and GenePop software (Raymond \& Rousset, 1995). Expected and observed heterozygosities $\left(\mathrm{H}_{\mathrm{o}}\right.$ and $\mathrm{H}_{\mathrm{e}}$ ) (Nei, 1987), polymorphic information content (PIC) (Botstein et al., 1980), and fixation index $\left(\mathrm{F}_{\mathrm{ST}}\right)$ were calculated basing on detected alleles. The rest of coefficients were estimated on the basis of method suggested by Huston (1998) in own-made software: power of discrimination (PD), combined probability of exclusion (PE), and probability of exclusion with assuming of presence of both paternal genotypes and probability of exclusion, when one of paternal genotypes is known (respectively $\mathrm{PE}_{2}$ and $\mathrm{PE}_{1}$ ) (Huston, 1998).

\section{RESULTS AND DISCUSSION}

The fixation index $\left(\mathrm{F}_{\mathrm{ST}}\right)$ - measure of population differentiation due to genetic structure was estimated. Because of $\mathrm{F}_{\mathrm{ST}}$ coefficient has been qualify as low (lower than $5 \%$ - range from 0.0853 to 0.0531 ), thus, it was not differentiation among subpopulations, and all three populations were estimated as a one population in following analyses. Entire set of 17 microsatellites loci was polymorphic and total number of 112 different alleles in 17 loci was detected. The number of alleles was estimated per particular loci and mean number of alleles was $7(7.00 \pm 1.62)$ (the table with all allele frequencies is available from the authors on request). The most polymorphic loci were VHL20 and ASB17 with 9 allelic variants, the least polymorphic - HTG4 and HTG6 with 4 allelic variants. Number of detected alleles was similar to research of the Georgescu et al. (2008) in which mean number of Romanian Hucul horse population using twelve basic microsatellites loci was 6.66 alleles per locus. Comparably to Kusza et al. (2013) research based on seventeen microsatellites loci, mean number of alleles was little less than result in this study. According to Kusza et al. (2013), mean number of alleles reported was close to the mean numbers for breeds as Indian Spiti horse (4.8), Hungarian Lipizzan (5.8), Croatian Lipizzan (5.2), Spanish Trotter horses (6.0), but lower than reported for the Pantaneiro horse (9.1) and Mediterranean horse (10.6). The differences among breeds and their mean numbers of alleles could depend on analysed number of alleles, number of individuals in study, or particular population structure.

The observed and the expected heterozygosities $\left(\mathrm{H}_{\mathrm{o}}\right.$ and $\mathrm{H}_{\mathrm{e}}$ ), the polymorphic information content (PIC) were estimated. The results are presented in Table 2.

Mean number of expected heterozygosities was established as 0.7027 , observed heterozygosities was 0.7288 and polymorphic information content was 0.6661. Result of expected heterozygosities in this research was established quite similar to Kusza et al. (2013) results

Table 2. Polymorphic coefficients for all loci in 17 STR set - observed and expected heterozygosities, the polymorphic information content

\begin{tabular}{|c|c|c|c|}
\hline Locus & $\mathrm{H}_{\mathrm{e}}$ & PIC & $\mathrm{H}_{\mathrm{o}}$ \\
\hline AHT4 & 0.8148 & 0.7882 & 0.8565 \\
\hline AHT5 & 0.7237 & 0.6906 & 0.7546 \\
\hline ASB2 & 0.7732 & 0.7393 & 0.8380 \\
\hline HMS2 & 0.6179 & 0.5876 & 0.5787 \\
\hline HMS3 & 0.8042 & 0.7803 & 0.8287 \\
\hline HMS6 & 0.7876 & 0.7529 & 0.8333 \\
\hline HMS7 & 0.6822 & 0.6301 & 0.6898 \\
\hline HTG10 & 0.7364 & 0.6985 & 0.8056 \\
\hline HTG4 & 0.6634 & 0.6006 & 0.6574 \\
\hline HTG6* & 0.3849 & 0.3578 & 0.4213 \\
\hline HTG7* & 0.5930 & 0.5412 & 0.6898 \\
\hline VHL20 & 0.8420 & 0.8209 & 0.9259 \\
\hline ASB17 & 0.8406 & 0.8191 & 0.9120 \\
\hline ASB23 & 0.5900 & 0.5254 & 0.6481 \\
\hline CA425* & 0.8419 & 0.8196 & 0.8148 \\
\hline $\mathrm{HMS1}^{*}$ & 0.7571 & 0.7188 & 0.7778 \\
\hline LEX3* & 0.4922 & 0.4532 & 0.3565 \\
\hline Mean value & 0.7027 & 0.6661 & 0.7288 \\
\hline \pm S.D. & $\pm 0,1315$ & $\pm 0,1378$ & $\pm 0,1597$ \\
\hline
\end{tabular}

${ }^{*}$ Additional microsatellites markers in STRs set 
Table 3. Polymorphic coefficients for all loci in 17 STR set power of discrimination, combined probability of exclusion, probability of exclusion for one known paternal genotype and of both genotypes

\begin{tabular}{|c|c|c|c|c|}
\hline Locus & PD & $\mathrm{PE}$ & $\mathrm{PE}_{1}$ & $\mathrm{PE}_{2}$ \\
\hline AHT4 & 0.9296 & 0.7077 & 0.4566 & 0.6329 \\
\hline AHT5 & 0.8850 & 0.5177 & 0.3307 & 0.5146 \\
\hline ASB2 & 0.9105 & 0.6713 & 0.3911 & 0.5697 \\
\hline HMS2 & 0.7973 & 0.2661 & 0.2274 & 0.4102 \\
\hline HMS3 & 0.9346 & 0.6534 & 0.4491 & 0.6277 \\
\hline HMS6 & 0.9077 & 0.6623 & 0.4011 & 0.5798 \\
\hline HMS7 & 0.8460 & 0.4127 & 0.2633 & 0.4329 \\
\hline HTG10 & 0.8822 & 0.6094 & 0.3357 & 0.5166 \\
\hline HTG4 & 0.8260 & 0.3655 & 0.2388 & 0.3973 \\
\hline $\mathrm{HTG}^{*}{ }^{*}$ & 0.6037 & 0.1274 & 0.0763 & 0.2102 \\
\hline $\mathrm{HTG}^{*}$ & 0.7721 & 0.4127 & 0.1870 & 0.3475 \\
\hline VHL20 & 0.9452 & 0.8486 & 0.5140 & 0.6826 \\
\hline ASB17 & 0.9480 & 0.8201 & 0.5109 & 0.6797 \\
\hline ASB23 & 0.7518 & 0.3527 & 0.1834 & 0.3303 \\
\hline CA425* & 0.9521 & 0.6268 & 0.5073 & 0.6775 \\
\hline $\mathrm{HMS}^{*}{ }^{*}$ & 0.8890 & 0.5585 & 0.3602 & 0.5393 \\
\hline LEX3* & 0.6745 & 0.0896 & 0.1280 & 0.2804 \\
\hline
\end{tabular}

*Additional microsatellites markers in STRs set

(0.706) and to Žídek et al. (2009) result (0.767). Greater heterozygosities value was observed in comparison with Georgescu et al. (2008) result for Romanian Hucul population (0.662) and Žídek et al. (2009) (0.675). According to Kusza et al. (2013) result of heterozygosities about 0.7 was average in comparison to other horses breeds heterozygosities values.

Most of polymorphic coefficients were over 0.5 , beyond two loci HTG6 and LEX3, which belong to additional loci in recommended parentage control set of STRs for horses. 10 loci were observed as the most polymorphic (assuming values $\mathrm{H}_{\mathrm{e}}$, PIC, $\mathrm{H}_{\mathrm{o}}$ over 0.7 ). The value of expected heterozygosities for HTG6 loci was lower than observed and the similar situation was for LEX3 loci: 0.3849 (expected) and 0.4213 (observed) for HTG6, 0.4922 and 0.3565 for LEX3, respectively. The most significant difference between $\mathrm{H}_{\mathrm{o}}$ and $\mathrm{H}_{\mathrm{e}}$ was also observed for LEX3. In LEX3 marker inaccuracy were observed in Zabek et al. (2009) study as well, probably because of linkage of this microsatellite to X-chromosome. Most likely, the greatest differences between $\mathrm{H}_{\mathrm{o}}$ and $\mathrm{H}_{\mathrm{e}}$ values characteristic of locus LEX3 are connected to the location on X-chromosome. The mean inbreeding index value $\left(\mathrm{F}_{\mathrm{IS}}\right)$ was estimated as -0.093 . The inbreeding index values for all loci were negative except for LEX3. The values for particular loci were calculated from -0.195 for HTG7 to 0.222 for LEX3 (data not shown). The value for LEX3 loci is probably encumbered with error because of its linkage to X-chromosome. Hence, inbreeding index value except LEX3 loci data indicates the Hucul horse population is not inbreeding. The power of discrimination (PD) of analysed set of loci was tested. The combined probability of exclusion (PE) was calculated with assumption of presence of both
Table 4. Combined probability of exclusion and probability of exclusion for one known paternal genotype and both paternal genotypes for set of twelve basic microsatellites loci

\begin{tabular}{llll}
\hline Locus & $\mathrm{PE}$ & $\mathrm{PE}_{1}$ & $\mathrm{PE}_{2}$ \\
\hline AHT4 & 0.7077 & 0.4566 & 0.6329 \\
\hline AHT5 & 0.5177 & 0.3307 & 0.5146 \\
\hline ASB2 & 0.6713 & 0.3911 & 0.5697 \\
\hline HMS2 & 0.2661 & 0.2274 & 0.4102 \\
\hline HMS3 & 0.6534 & 0.4491 & 0.6277 \\
\hline HMS6 & 0.6623 & 0.4011 & 0.5798 \\
\hline HMS7 & 0.4127 & 0.2633 & 0.4329 \\
\hline HTG10 & 0.6094 & 0.3357 & 0.5166 \\
\hline HTG4 & 0.3655 & 0.2388 & 0.3973 \\
\hline VHL20 & 0.8486 & 0.5140 & 0.6826 \\
\hline ASB17 & 0.8201 & 0.5109 & 0.6797 \\
\hline ASB23 & 0.3527 & 0.1834 & 0.3303 \\
\hline
\end{tabular}

paternal genotypes, and also probability of exclusion, when one of paternal genotype is known $\left(\mathrm{PE}_{2}\right.$ and $\left.\mathrm{PE}_{1}\right)$ (Huston, 1998) (Table 3).

All loci had high value PD (over 0.7), except of two microsatellite markers. The lowest value was calculated for LEX3 and HTG6 as well as observed for PIC coefficients (0.6745 and 0.6037 , respectively). The cumulative power of exclusion for whole set of loci was estimated as 0.999999 . The power of cumulative exclusion, when one of paternal genotype is known, was 0.999158 for all set of 17 STRs. The value of coefficient when both paternal genotypes were known, was higher and estimated as 0.999996. For particular loci PE coefficients values were the lowest for LEX3 and HTG6 loci. Nevertheless, cumulative power of exclusion for all set of microsatellite loci is very high $(99.9999 \%)$.

Analysis of twelve basic microsatellites loci was also conducted (Table 4). The cumulative power of exclusion for basic set of loci was estimated as 0.999989 . The power of cumulative exclusion, when one of paternal genotype is known, was 0.995919 for basic set of 17 STRs.

The combined probability of exclusion with assumption of presence of both known paternal genotypes, was estimated for basic set of loci as 0.999920 , and it was a little less value than whole set of 17 STRs (0.999996).

\section{CONCLUSIONS}

The subject of analysis was Hucul horse population consisted of three separated studs. Entire set of analysed microsatellites loci is useful for individual identification and parentage testing in analysed Hucul horse population. Lower polymorphism of HTG6 loci does not have much influence for utility of whole 17 microsatellite loci set. Despite of small number of individuals in this studs, the high values of polymorphism coefficients of population indicate usefulness of analysed set of STRs in parentage control testing even for small populations. Moreover, the analysis between whole set of loci and basic set of loci indicated more confidence in parentage testing cases, particularly in small populations analysis. The using of seventeen microsatellite set of loci provides greater certainty of parentage testing. 
The results of Hucul horse previously researched indicate the similar mean number of alleles per locus which was higher than reported in literature for other breeds. There is a divergence between the utility and maintenance of breeding, and an effect of improvement of utility traits by selection efforts. Implementation of these breeding goals could provide to reducing of genetic diversity. On the other hand, restricted approach to breeding conservation could lead to declining some utility traits.

Generally, small populations like subject of this study, have always greater risk of inbreeding and losing of genetic information. The selection should be carried out in order to avoid inbreeding depression.

This preliminary results of analysis is the first genetic diversity study of Hucul horse in Poland. Next step of research would be inter alia analyses of larger number of studs and individuals, and also mtDNA sequences. Genetic diversity of Hucul horse as indigenous breeds in Poland should be monitored to preserve biodiversity.

\section{REFERENCES}

Bordzoł A, Jackowski M (2008) Struktura genealogiczna populacji koni huculskich w Bieszczadzkim Parku Narodowym. Roczniki bieszczadzkie 16: 389-408 (in Polish).

Botstein D, White RL, Skolnick M, Davis RW (1980) Construction of a genetic linkage map in man using restriction fragment length polymorphisms. Am J Hum Genet 32: 314-331.

DAD-IS (Domestic Animal Diversity Information System hosted by FAO) (2013.09.12). http://dad.fao.org.

Dimsoski P (2003) Development of a 17-plex microsatellite polymerase chain reaction kit for genotyping horses. Croatian Medical Journal 44: 332-335.

Equine Genetics and Parentage Analysis Workshop (2012) Equine Genetics \& Thoroghbred Parentage Testing Standardisation Workshop. http://www.isag.us/Docs/EquineGenParentage2012.pdf: 1-14.

Georgescu SE, Costache M (2012) Genetic characterization of romanian local breeds using microsatellite markers. In Analysis of Genetic Variation in Animals. Chapter 2: 27-44.
Georgescu SE, Manea MA, Costache M (2008) The genetic structure of indigenous Romanian Hucul horse breed inferred from microsatellite data. Roumanian Biotechnological Letters 13: 4030-4036.

Georgescu SE, Manea MA, Dudu A, Costache M (2011) Phylogenetic relationships of the Hucul horse from Romania inferred from mitochondrial D-loop variation. Genet Mol Res 10: 4104-4113.

Huston, KA (1998) Statistical analysis of STR data. Profiles in DNA 3: 14-15.

Instruction Manual, Equine Genotypes ${ }^{\mathrm{TM}}$ Panel 1.1 (2011), http://diagnostics.finnzymes.fi/equine_genotypes.html

Józsa C, Bán B, Mihók S, Bodó I (2005) DNA microsatellite test of Hutsul horses in Hungary. EAAP - 56th Annual Meeting.

Kusza S, Priskin K, Ivankovic A, Jedrzejewska B, Podgorski T, Jávor A, Mihók S (2013) Genetic characterization and population bottleneck in the Hucul horse based on microsatellite and mitochondrial data. Biological Journal of the Linnean Society 109: 54-65.

Nei M (1987) Molecular Evolutionary Genetics. Columbia University Press.

Peakall R, Smouse PE (2006) GENALEX 6: genetic analysis in Excel. Population genetic software for teaching and research. Molecular Ecology Notes 6: 288-295.

Raymond M, Rousset F (1995) GENEPOP (version 1.2): Population genetics software for exact tests and ecumenicism. J Heredity 86: 248-249.

Tautz D (1989) Hypervariability of simple sequences as general source for polymorphic DNA markers. Nucleic Acids Res 17: 6463-6471.

Tomczyk-Wrona I (2009) Program ochrony zasobów genetycznych koni huculskich. 2013.09.12 http://www.bioroznorodnosc.izoo.krakow.pl/konie/programy-ochrony (in Polish).

Trandžík J, Žídek R, Jakabová D, Buleca J, Massányi P, Haško M, Kozlík P (2006) Genetic diversity of Hucul horse, based on microsatellite data in Slovak Republic. http://www.raumberggumpenstein.at $/ \mathrm{c} /$ index.php?option $=$ com_docman\&task $=\mathrm{doc}$ view\&gid $=2344 \&$ Itemid $=100014$.

Van de Goor LHP, Panneman H, van Haeringen WA (2010) A proposal for standardization in forensic equine DNA typing: allele nomenclature for 17 equine-specific STR loci. Animal Genetics 41: 122-127.

Ząbek T, Fornal A (2009) Evaluation of the 17-plex STR kit for parentage testing of polish Coldblood and Hucul horses. Ann Animal Sci 9: 363-372.

Žídek R, Jakabová D, Trandžik J, Gralak B, Burócziová M, Buleca JJr, Maróti-Agóts A, Massányi P, Dvorăk J, Rỉha J, Zöldág L (2009) Diversity analysis of Hucul horse population based on molecular genetic data. Magyar Állatorvosok Lapja 131: 685-691. 